\title{
Probabilistic perception, empathy, and dynamic homeostasis: insights in autism spectrum disorders and conduct disorders
}

\author{
Jean Marc Guilé* \\ Groupe de Recherches sur l'Analyse Multimodale de la Fonction Cérébrale, INSERM 1105, Université Picardie Jules Verne, Amiens, France
}

\section{Edited by:}

Richard Eugene Frye, Harvard

University, USA

Reviewed by:

Dio Jurecska, Kaiser Foundation Hospitals, USA

Tammy Chung, University of

Pittsburgh Medical Center, USA

David Cohen, Université Pierre et

Marie Curie, France

${ }^{*}$ Correspondence:

Jean Marc Guilé, Child and

Adolescent Psychopathology

Department, CHU, Place Victor

Pauchet, 80000 Amiens, France

e-mail: guile.jean-marc@chu-

amiens.fr

Autism spectrum disorders (ASD) and conduct disorders (CD) are both of public health concern. Prevalence for ASD reaches $0.7 \%$ in general population (1), while CD bears high social burden, especially CD with high callous-unemotional traits (CD-HCU), with elevated rate of violent crime. Both disorders are associated with social maladjustment and impaired communication and empathy. Within an evolutionary perspective, empathy is an adaptive response to the continuously challenging social environment and an efficient means to reach homeostasis. With respect to key concepts such as homeostasis, perception, and synchrony, the present article will review the development of empathy in typicallydeveloped (TD) youth before addressing empathy impairments pertaining to ASD and CD-HCU.

\section{DYNAMIC HOMEOSTASIS AND EMPATHY}

Homeostasis, which is marked by extreme instability according to Cannon (2), cannot be obtained without exchanges with the environment. Disequilibrium is a basic characteristic of human beings. Humans cannot survive on their own and must engage in dynamic exchanges with their physical and human environment. Revisiting Cannon's definition of homeostasis, Arminjon et al. (3) appropriately stressed that homeostasis is not referring to a permanent and stable state but instead results from the interaction of conflicting forces. The newborn's innate propensity to communicate with other humans allows for searching the biological, cognitive, and affective inputs required for his/her development. Empathy encompasses the cognitive mechanisms, which provide security and cohesiveness among these conflicting interactions. Such mechanisms have been traced back in primates and other mammals $(4,5)$. From an evolutionary standpoint, empathy is an adaptive mechanism to help secure individuals' development and survival.
Empathy refers to the intuitive access to others' subjective experience (6). It denotes the individual's capacity to understand others' intents and experience their feelings. Empathy is currently conceived as a cognitive capacity, which supports individuals' ability to behave with respect to socially relevant information. Empathy is not a unitary function and encompasses three processes, which successively appear as the child matures: procedural/implicit, semantic, and biographical empathy. Procedural empathy refers to the innate and non-conscious capacity to resonate with others' emotional states. Procedural empathy itself encompasses three components seen in neonates and primates: sensorimotor resonance, also called motor contagion, emotional arousal/contagion, and empathetic concern. Sensorimotor resonance supports behavioral (7) and neural (8) mirror activations. Emotional arousal is the emotional contagion resulting in similar emotion being aroused in the observer as a response to the expressed emotion of another (8). Empathetic concern is an "other-oriented emotional response congruent with the perceived welfare of someone in need" (8). It results from the attachment system, which develops between the infant and his/her primary caregivers (9). Semantic empathy parallels language development and expresses connection between words, meaning, and emotion. All these processes take place before the installation of theory of mind when the child turns four. Biographical empathy emerges later in life and corresponds to the interweaving of personal experience with feelings and words, together with a capacity to bridge with others' experiences.

Over the past decade, electrophysiological (ERP) and neuroimaging studies, especially on others' pain perception, have shed light on the neural underpinnings of empathy. Because emotions are expressed through facial mimicry, the neural circuitry of empathy lies at the crossroads of networks involved in attention, 
emotional arousal, face perception, intent recognition and selfawareness (agency). Pain ERP studies have elicited a very early response occurring at $60 \mathrm{~ms}$ after exposure to a painful visual stimulus $(10,11)$. High-density ERP with brain source analysis techniques identified the signal source in the right temporo-parietal junction (TPJ), a cortical area bridging visual and attentional cortical pathways with amygdala and prefrontal networks. Such activation discriminated between intentional and accidental harmful behaviors. Previous neuroimaging studies conducted by the same group have identified TPJ as a pivotal network in discriminating self and other actions (agency) (8). Later potentials have been identified around $120 \mathrm{~ms}$ after stimulus onset over the amygdala or the anterior cingulum depending on the study. This $120 \mathrm{~ms}$ negativity is usually viewed as arousal response combining attentional and emotional reactiveness. Of note, negative potentials occurring around $170 \mathrm{~ms}$ after stimulus onset are specifically associated with face processing (12). Later activations denote prefrontal recruitments and contributions from top-down regulation mechanisms. In sum, ERP studies point to the earliness of cognitive responses triggered by the intent and emotional value associated with the stimulus, even before its shape and identity are fully disclosed.

Neuroimaging studies on empathy for pain provide results complementary to ERP data. FMRI studies have consistently stressed the association between empathy and activation of regions such as the anterior insula, anterior cingulate, and amygdala. On the contrary, the involvement of sensorimotor areas is still unclear. Studies diverge on whether pain direct and vicarious experiences recruit the same brain sensorimotor and limbic networks. Observing pain in someone else is associated with partial activation of the pain matrix recruited when experiencing oneself pain, namely anterior insula/fronto-insular cortex and the anterior cingulate cortex (13). Activation of the sensorimotor and somatosensory cortices seemed to be restricted to direct painful experiences. Recent studies, however, have shown the activation of sensory cortices (14) and motor cortices (15) in perception of other's pain. These findings lent support to the existence of a separate although empathy-related network responsible for sensorimotor contagion. In sum, apart from subcortical structures as amygdala, empathy networks encompass prefrontal and anterior cingulate cortices as well as interconnected areas like insula and TPJ. These cortical networks indirectly receive information from visceral sensory systems about internal homeostasis, which impacts their activation (16).

\section{PROBABILISTIC PERCEPTION AND PARENT-INFANT SYNCHRONY}

Infant's early empathy behaviors rely on non-conscious and innate procedural/implicit cognitive processes, which themselves depend on the perception of auditory and visual social cues. Such cues attest to the presence of care givers in the infant's environment. Although sensory inputs are basically continuous and ambiguous, infants as young as 8-month-old have been shown to be capable of word discrimination. This capability seems to result from statistical learning processes (17). Infants can detect within the continuous voice flow statistical patterns (e.g., pairwise association between letters and syllables) that serve as a cue to word boundaries $(18,19)$. Each sensory input gives rise not only to one interpretation but also to a large range of inferences regarding the true state of the perceived environment (20). This probabilistic perception allows for building up an internal model of rhythms, objects, and people, which are the source of sensory inputs. This internal model is subsequently modified according to subsequent sensory inputs.

In naturalistic settings, subsequent inputs are provided through interactions between parents and infant. Parents' vocalizations, called infant-directed-speech (IDS) or motherese (21), trigger the infant's vocalizations, which in turn lead to parental responses. As observed in family home videos, parents and infant interactions gradually evolve toward a synchronous pattern of mutual attention, speech, and gestures without any conscious intent from the participants (22). Following Delaherche et al. (23), synchrony could be viewed as the dynamic and reciprocal adjustment to the temporal structure of interactive behaviors and emotions between communication partners, e.g., mother and infant smiling at each other and babbling together during feeding time. Synchrony, which constitutes the core phenomenon of empathy, is probably the main factor sustaining probabilistic perception and learning. Infants identify probabilistic patterns within verbal interactions with their parents. How such patterns of co-occurring vocal sounds get selected and merged with the infant's internal model of the perceived environment? One could stress the frequency of these co-occurrences. Another explanation would be that the parental synchronous response operates as a validation of the infant's probabilistic perception mechanisms. Synchrony induces a selection within the perception inferences aroused by sensory inputs. Consequently, it enhances the formation of shared representations of the perceived verbal environment between infant and parents. It could be one of the mechanisms by which social interaction affects implicit learning (24). According to this hypothesis, synchrony would foster language acquisition in non-verbal infants.

Synchrony not only implies cognitive but also bodily processes. Damasio (16) emphasized the involvement of brain-body pathways, including autonomous nervous system, which shape composite and dynamic maps of the body's state from moment to moment. Biological expressions of synchrony have been consistently demonstrated through vagal tone modulation and oxytocin secretion during mother-infant interactions $(25,26)$.

In keeping with the framework of dynamic homeostasis, probabilistic perception theory gives to perception, a definite characteristic of incompleteness and disequilibrium. Such mechanisms require, in turn, appropriate response from the environment to achieve adequate perception. Homeostasis is achieved through synchronous non-conscious exchanges between parents and infant. Synchrony is the common basic mechanism, which underlies mirror mechanisms observed at neural and cognitive levels in neuroimaging and ERP studies on empathy.

\section{EMPATHY AND DYNAMIC HOMEOSTASIS IN TYPICALLY DEVELOPED INFANTS}

Decety and Svetlova (8) put together ontegenetic and phylogenetic perspectives to set up an evolutionary model of the development of empathy. Several adaptations of cognitive processes, both procedural/implicit and explicit, have been added to the social brain across evolution. Rather than ended up with a well coordinated structure of empathy mechanisms, it seemed that evolution led 
to a "patchwork of additions" encompassing various processes, each with a distinct evolutionary history and neural networking, and a parallel although interdependent functioning. Among the procedural mechanisms, self-awareness (agency), which allows for discriminating between self-generated actions and others' behaviors, seems to be human-specific. Other human-specific mechanisms, like explicit processes, which prevent emotional upsets and regulate emotional concern capacities, operate gradually over the child development according to caregivers inputs. Such a complex and interactive construct allows for a wide range of flexibility and adaptive responses to environmental challenges.

Synchrony, which plays a pivotal role in developing empathy, stems from early interactions in utero and all across infant development since birth. It affects the infant's first perceptions whatever the different sensory modalities and triggers unimodal and crossmodal parental responses, although studies report mainly on auditory and visual social stimuli. Premature babies present syllabic discrimination capacities and voice recognition by the 28th week of gestation (27) and the fetuses show indication of maternal voice recognition in by the 34 th week of gestation (28). A pattern of synchronous parent-infant vocalizations has been observed in family home videos with TD infants showing the impact of synchrony on infant language development (21). During second semester, the parents' motherese (vs. other speech) is significantly followed by more infant's vocalizations. In a recent neuroimaging study, synchrony was associated with mother's brain activations in the dorsal anterior cingulate (dACC), cuneus, fusiform, supplementary motor and TPJ cortices, dACC being the most sensitive area to the mother's synchronous response to her infant (29).

With regard to visual processing, first-trimester-old neonates demonstrate preference for the upper part of human faces and gaze-following capacities. By 6-months of age, infants allocate increased attention to angry faces with direct eye gaze as well as to fearful faces looking toward objects and objects that are gazecued by a fearful face $(30,31)$. Behavioral sensorimotor resonance, the capacity to imitate complex specific facial mimicry, has been shown in newborns as early as a few days-old infants (7). This automatic mimicry disappears by 3 -months of age as these implicit mechanisms are replaced by more adaptive responses proper to the particular affective context of interactions between the infant and his/her caregivers. Twelve-month-old infants tend to read other humans' intentions beyond the observed behavior and attribute discriminate goals to others $(32,33)$. These results, pointing to early forms of self-awareness, are consistent with experiments demonstrating the infant's early discriminate reactivity to his/her own recorded cry in comparison to the cry of another baby (34). More elaborated and explicit self-awareness/agency processes later develop in the second year of life alongside perspective-taking increasing capabilities (35) and spatial abilities (36).

Taken together, it seems that neonates are cognitively equipped to detect environmental threats and others' intents. On the opposite, their capability to respond adaptively to such inputs depends on the context, especially the ability of their human environment to decode in return their emotion and intent to perform actions. As a consequence, automatically elicited implicit detection and response processes tend to vanish over the course of infant development to be replaced by contextually developed more adaptive mechanisms with regard to the specific context of the infant's relationships with his/her caregivers. At birth perceptual and neural systems are wired to be sensitive to social information, and with age prefrontal and limbic networks get more matured and connected, allowing for more contextually and experience-driven interactions (8). These developmental processes allow for achieving proper dynamic homeostasis.

\section{EMPATHY AND DYNAMIC HOMEOSTASIS IN AUTISM SPECTRUM DISORDERS}

Autism spectrum disorders are associated with major impairments in social communication and adaptation, as well as selfawareness/agency immaturity (37). Disturbances and alternative cognitive processes affecting perception and empathy, especially procedural systems, have been identified over the past decades. These cognitive characteristics put the ASD child's homeostasis achievements at stake (Figure 1). The child often asks for repetitive activities and interactions while relying mainly on personal inputs, rather than bridging with others, to maintain homeostasis.

In keeping with seminal studies of Saffran et al. (18), research has been conducted to explore probabilistic perceptual mechanisms used in ASD (38). Individuals with ASD are less susceptible of perceptual illusions and less influenced by acquired expertise on perceived objects. Since perception in ASD is less constraint by previously memorized organization of sensory inputs, it might slow down new acquisition and adaptation in ordinary social context while providing more perceptual accuracy in unexpected situations.

Spontaneous mimicry, observed in TD infants, is lacking in ASD (39) whereas voluntary mimicry is often preserved (40). Sensorimotor resonance, as measured by spectral EEG (41) and ERP $(15,42)$ is impaired in ASD. In a study on self and other pain perception, in contrast to TD participants, adults with Asperger Disorder did not show any modification of motor-evoked potentials corresponding to the muscle vicariously affected by pain (15). Since mimicry and facial emotion discrimination implied recruiting somatosensory-related cortices (42), impairment in facial emotion detection observed in ASD could be related to a lack of activation of sensorimotor cortical networks.

Behavioral as well as neuroimaging studies on fearful facial emotion have elicited an abnormal pattern of emotional arousal. Individuals with ASD, adults (43), and children (35), gazed more often away from than toward the eyes in comparison with a TD group. ASD adults showed increased amygdala activity when the eyes included in the fearful facial stimulus appeared at the initial location of the fixation point, compared with initial fixation at the mouth and compared with the TD individuals (43). In the experiment, increased initial amygdala activation was associated with subsequent gazing off the fearful stimulus. This reaction pattern differs from TD infants whose attention is attracted by fearful faces.

At first glance, semantic empathy seemed to be less impacted in ASD, since behavioral studies using facial emotion categorization tasks did not yield significant differences between ASD and TD groups, even when using multimodal sensory inputs (44). However, significant differences were retrieved when the experiments imply a sequential presentation of the stimuli, thus involving a 


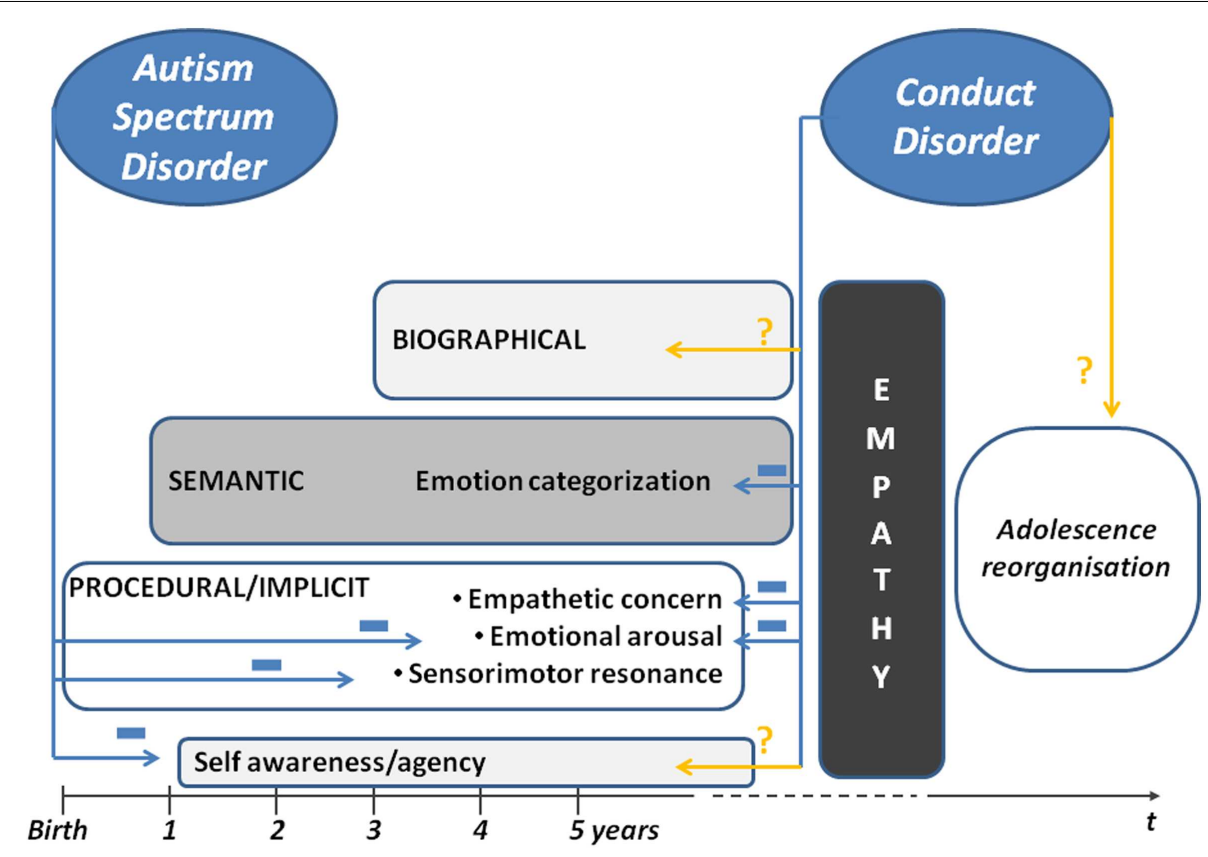

FIGURE 1 | Development of empathy in early childhood.

working memory component (45). This result is consistent with observations from Pellicano and Burr (38) on visual expertise. In addition, neuroimaging studies stressed the alternative recruiting strategies observed in ASD adults and children. In comparison to TD participants, ASD children showed less activation in fusiform gyrus (46), an area which would undergo cortical thinning later in child development (47). It suggests that ASD children use more configurational and less emotion-driven information than TD while processing facial emotion (46).

A wide area is offered to further researches, including the exploration of synchronous social processing between ASD children and their caregivers in order to assess the impact of synchrony on social learning. Analyses of naturalistic home videos with infants, who later developed ASD already showed an increase in parental stimulation and IDS during the second semester (48). Clinical observations tend to support that attachment processes, and consequently empathetic concern, the third component of procedural empathy, are relatively preserved despite some impairments in the perception of others' needs. Therefore given procedural empathy impairments, homeostasis dynamics in family affected with ASD would be modified, offering the child with more adaptive parental homeostatic responses.

\section{EMPATHY AND DYNAMIC HOMEOSTASIS IN CONDUCT DISORDERS WITH HIGH CALLOUS-UNEMOTIONAL TRAITS}

Conduct disorders with high callous-unemotional traits (CD$\mathrm{HCU}$ ), also called psychopathy, is a CD subgroup with a restricted emotional expression, callous lack of regard for others, and severe violent behavior against people (49). Although the complete syndrome appears in childhood with later reorganization related to the evolution of peer-relationships in adolescence, precursors can be traced back to infancy [for a review see Ref. (50)]. A few studies, exploring empathy, have been conducted on pain detection and facial emotion processing.

Sensorimotor resonance, as measured by attenuation of the $\mu$ band (8-12 Hz in central region), appeared unaffected in both CD-HCU and CD-LCU male adolescents while observing pain in others (51). However, no frontal N120 increase was observed in $\mathrm{CD}-\mathrm{HCU}$, indicating attenuated emotional arousal compared to TD and CD-LCU controls. While processing pain, CD-HCU participants exhibited significantly less activation in the ventromedial prefrontal cortex and lateral orbitofrontal cortex, but greater activation in the insula, compared with CD-LCU (52). Low emotional arousal was equally observed in Adolescents with CD-HCU, while processing fearful faces compared to CD-LCU and TD controls (53). Clinical observations indicate that empathy concern, another procedural empathy process which is related to attachment, is impaired. Parental deficits in empathy, which were known to contribute to CD in their offspring $(50,54)$, might impede the development of a proper attachment system and consequently mediate the lack of emotional concern observed in CD-HCU children. Deficits in semantic empathy have been consistently found in CD, namely fear-recognition deficit and hostility bias in labeling facial emotion $(55,56)$ [for a review see Ref. (57)]. In addition, impairments in biographical empathy would be expected, given the association between early life adversities and child maltreatment, and CD (58).

In sum, several components of procedural empathy are affected in $\mathrm{CD}-\mathrm{HCU}$ compared to $\mathrm{CD}-\mathrm{LCU}$ and controls. Emotional arousal for pain and fear is decreased as well as empathetic concern. Semantic empathy is impaired with a propensity to dismiss fearful faces and label neutral faces as hostile (Figure 1). 


\section{IMPLICATIONS FOR TREATMENT}

Recent pilot studies on short-term remediation programs addressing specific ASD empathy impairments yielded promising results with measurable improvements in face processing skills of ASD children (59). Given the decrease in emotional arousal and semantic empathy for fear observed in psychopathy, computerized cognitive remediation has been proposed to CD-HCU youths, training them to focus on the eyes of fearful faces. Pilot studies showed that such cognitive remediation programs can ameliorate fear-recognition deficits $(53,56)$.

\section{CONCLUSION}

If TD neonates are fully equipped to synchronously interact with their human environment, ASD and CD-HCU present with disturbances in emotional arousal and facial emotion processing. In addition sensorimotor resonance is lacking in ASD, and emotional concern and semantic empathy are impaired in CD-HCU. These impairments prevent ASD and CD-HCU to achieve proper homeostasis. Further research is needed for exploring probabilistic perception mechanisms in these clinical populations on the one hand and, on the other hand, investigating patterns of coactivation between mother and infant with neuroimaging and electrophysiology.

\section{ACKNOWLEDGMENTS}

The author thanks Dr. Jemel and Dr. Decety for previous discussion on empathy, and Prof. Cohen for lending his pictorial skills.

\section{REFERENCES}

1. Fombonne E. Epidemiology of pervasive developmental disorders. Pediatr Res (2009) 65:591-8. doi:10.1203/PDR.0b013e31819e7203

2. Cannon WB. The Wisdom of the Body. New York: W.W. Norton, Cop. (1932).

3. Arminjon M, Ansermet F, Magistretti P. The homeostatic psyche: Freudian theory and somatic markers. J Physiol Paris (2010) 104:272-8. doi:10.1016/j. jphysparis.2010.08.006

4. de Waal FB. Putting the altruism back into altruism: the evolution of empathy. Annu Rev Psychol (2008) 59:279-300. doi:10.1146/annurev.psych.59.103006. 093625

5. Hamann K, Warneken F, Greenberg JR, Tomasello M. Collaboration encourages equal sharing in children but not in chimpanzees. Nature (2011) 476:328-31. doi:10.1038/nature10278

6. Guilé JM. Disentangling cognitive processes from neural activation and psychic mechanisms: the example of empathy. J Physiol Paris (2010) 104:337-41. doi:10.1016/j.jphysparis.2010.09.001

7. Meltzoff AN, Moore MK. Explaining facial imitation: a theoretical model. Early Dev Parent (1997) 6:179-92. doi:10.1002/(SICI)1099-0917(199709/12)6: 3/4<179::AID-EDP157>3.0.CO;2-R

8. Decety J, Svetlova M. Putting together phylogenetic and ontogenetic perspectives on empathy. Dev Cogn Neurosci. (2012) 2:1-24. doi:10.1016/j.den.2011.05.003

9. Guedeney A, Guedeney N, Tereno S, Dugravier R, Greacen T, Welniarz B, et al. Infant rhythms versus parental time: promoting parent-infant synchrony. JPhysiol Paris (2011) 105:195-200. doi:10.1016/j.jphysparis.2011.07.005

10. Decety J, Cacioppo S. The speed of morality: a high-density electrical neuroimaging study. J Neurophysiol (2013) 108:3068-72. doi:10.1152/jn.00473.2012

11. Ortigue S, Thompson JC, Parasuraman R, Grafton ST. Spatio-temporal dynamics of human intention understanding in temporo-parietal cortex: a combined EEG/fMRI repetition suppression paradigm. PLoS One (2009) 4:e6962. doi:10.1371/journal.pone.0006962

12. Jemel B, Coutya J, Langer C, Roy S. From upright to upside-down presentation: a spatio-temporal ERP study of the parametric effect of rotation on face and house processing. BMC Neurosci (2009) 10:100. doi:10.1186/1471-2202-10-100
13. Singer T, Seymour B, O’Doherty J, Kaube H, Dolan RJ, Frith CD. Empathy for pain involves the affective but not sensory components of pain. Science (2004) 303:1157-62. doi:10.1126/science.1093535

14. Avenanti A, Bueti D, Galati G, Aglioti SM. Transcranial magnetic stimulation highlights the sensorimotor side of empathy for pain. Nat Neurosci (2005) 8(7):955-60. doi:10.1038/nn1481

15. Minio-Paluello I, Baron-Cohen S, Avenanti A, Walsh V, Aglioti SM. Absence of embodied empathy during pain observation in Asperger syndrome. Biol Psychiatry (2009) 65(1):55-62. doi:10.1016/j.biopsych.2008.08.006

16. Damasio A. Mental self: the person within. Nature (2003) 423:227. doi:10.1038/ 423227a

17. Kuhl PK, Andruski JE, Chistovich IA, Chistovich LA, Kozhevnikova EV, Ryskina VL, et al. Cross-language analysis of phonetic units in language addressed to infants. Science (1997) 277(5326):684-6. doi:10.1126/science.277. 5326.684

18. Saffran JR, Aslin RN, Newport EL. Statistical learning by 8-month-old infants. Science (1996) 274:1926-8. doi:10.1126/science.274.5294.1926

19. Saffran JR. Words in a sea of sounds: the output of infant statistical learning. Cognition (2001) 81:149-69. doi:10.1016/S0010-0277(01)00132-9

20. Fiser J, Berkes P, Orbán G, Lengyel M. Statistically optimal perception and learning: from behavior to neural representations. Trends Cogn Sci (2010) 14:119-30. doi:10.1016/j.tics.2010.01.003

21. Saint-Georges C, Chetouani M, Cassel RS, Apicella F, Mahdhaoui A, Muratori F, et al. Motherese in interaction: at the cross-road of emotion and cognition? (A systematic review). PLoS One (2013) 8:e78103. doi:10.1371/journal.pone. 0078103

22. Trevarthen C, Stuart D. Disorganized rhythm and synchrony: early signs of autism and Rett syndrome. Brain Dev (2005) 27:S25-34. doi:10.1016/j.braindev. 2005.03.016

23. Delaherche E, Chetouani M, Mahdhaoui A, Saint-Georges C, Viaux S, Cohen D. Interpersonal synchrony: a survey of evaluation methods across disciplines. IEEE Trans Affect Comput (2012) 3:349-65. doi:10.1109/T-AFFC.2012.12

24. Meltzoff AN, Kuhl PK, Movellan J, Sejnowski TJ. Foundations for a new science of learning. Science (2009) 325:284-8. doi:10.1126/science.1175626

25. Feldman R, Eidelman AI. Maternal postpartum behavior and the emergence of infant-mother and infant-father synchrony in preterm and full-term infants: the role of neonatal vagal tone. Dev Psychobiol (2007) 49:290-302. doi:10.1002/dev.20220

26. Weisman O, Delaherche E, Rondeau M, Chetouani M, Cohen D, Feldman R. Oxytocin shapes parental motion during father-infant interaction. Biol. Lett (2013) 9:20130828. doi:10.1098/rsbl.2013.0828

27. Mahmoudzadeh M, Dehaene-Lambertz G, Fournier M, Kongolo G, Goudjil S, Dubois J, et al. Syllabic discrimination in premature human infants prior to complete formation of cortical layers. Proc Natl Acad Sci U S A (2013) 110:4846-51. doi:10.1073/pnas.1212220110

28. Jardri R, Houfflin-Debarge V, Delion P, Pruvo JP, Thomas P, Pins D. Assessing fetal response to maternal speech using a noninvasive functional brain imaging technique. Int J Dev Neurosci (2012) 30:159-61. doi:10.1016/j.ijdevneu. 2011.11 .002

29. Atzil S, Hendler T, Feldman R. The brain basis of social synchrony. Soc Cogn Affect Neurosci (2013). doi:10.1093/scan/nst105

30. Hoehl S, Striano T. Neural processing of eye gaze and threat-related emotional facial expressions in infancy. Child Dev (2008) 79:1752-60. doi:10.1111/j.14678624.2008.01223.x

31. Hoehl S, Striano T. The development of emotional face and eye gaze processing. Dev Sci (2010) 13:813-25. doi:10.1111/j.1467-7687.2009.00944.x

32. Cannon EN, Woodward AL. Infants generate goal-based action predictions. Dev Sci (2012) 15:292-8. doi:10.1111/j.1467-7687.2011.01127.x

33. Meltzoff AN. Understanding the intentions of others: re-enactment of intended acts by 18-month-old children. Dev Psychol (1995) 31:838-50. doi:10.1007/ s10339-012-0518-0

34. Dondi M, Simion F, Caltran G. Can newborns discriminate between their own cry and the cry of another newborn infant? Dev Psychol (1999) 35:418-26. doi:10.1037/0012-1649.35.2.418

35. Guilé JM, Droulin H, Rondeau E, Bon St-Come M, Berquin P, Hosein A, et al. Processing emotion and gaze direction of fearful faces in children with autistic disorders. Neuropsychiatrie Enf Adolesc (2012) 60:S94-5. doi:10.1016/j.neurenf. 2012.05 .391 
36. Xavier J, Bonnot O. Expérience fraternelle et diversité des points de vue: vers un modèle développemental et intégratif de l'empathie ? Neuropsychiatrie Enf Adolesc (2013) 61:51-9. doi:10.1016/j.neurenf.2012.09.006

37. Haag G. Post-Kleinian contribution to the concept of autism: the autism psychodynamic evaluation of changes scale (APEC scale). Neuropsychiatrie Enf Adolesc (2011) 60:S119. doi:10.1016/j.neurenf.2012.05.511

38. Pellicano E, Burr D. When the world becomes 'too real': a Bayesian explanation of autistic perception. Trends Cogn Sci (2012) 16:504-10. doi:10.1016/j.tics. 2012.08.009

39. Rogers SJ, Hepburn SL, Stackhouse T, Wehner E. Imitation performance in toddlers with autism and those with other developmental disorders. J Child Psychol Psychiatry (2003) 44:763-81. doi:10.1111/1469-7610.00162

40. McIntosh DN, Reichmann-Decker A, Winkielman P, Wilbarger JL. When the social mirror breaks: deficits in automatic, but not voluntary, mimicry of emotional facial expressions in autism. Dev Sci (2006) 9(3):295-302. doi:10.1111/j. 1467-7687.2006.00492.x

41. Bernier R, Dawson G, Webb S, Murias M. EEG mu rhythm and imitation impairments in individuals with autism spectrum disorder. Brain Cogn (2007) 64:228-37. doi:10.1016/j.bandc.2007.03.004

42. Adolphs R, Damasio H, Tranel D, Cooper G, Damasio AR. A role for somatosensory cortices in the visual recognition of emotion as revealed by threedimensional lesion mapping. J Neurosci (2000) 20:2683-90.

43. Kliemann D, Dziobek I, Hatri A, Baudewig J, Heekeren HR. The role of the amygdala in atypical gaze on emotional faces in autism spectrum disorders. J Neurosci (2012) 32:9469-9476. doi:10.1523/JNEUROSCI.5294-11.2012

44. Jones CR, Pickles A, Falcaro M, Marsden AJ, Happé F, Scott SK, et al. A multimodal approach to emotion recognition ability in autism spectrum disorders. JChild Psychol Psychiatry (2011) 52:275-85. doi:10.1111/j.1469-7610.2010. 02328.x

45. Weigelt S, Koldewyn K, Kanwisher N. Face identity recognition in autism spectrum disorders: a review of behavioral studies. Neurosci Biobehav Rev (2012) 36:1060-84. doi:10.1016/j.neubiorev.2011.12.008

46. Wang T, Dapretto M, Hariri AR, Sigman M, Bookheimer SY. Neural correlates of facial affect processing in children and adolescents with autism spectrum disorder. Am Acad Child Adolesc Psychiatry (2004) 43:481-90. doi:10.1097/00004583200404000-00015

47. Wallace GL, Dankner N, Kenworthy L, Giedd JN, Martin A. Age-related temporal and parietal cortical thinning in autism spectrum disorders. Brain (2010) 133:3745-54. doi:10.1093/brain/awq279

48. Cohen D, Cassel RS, Saint-Georges C, Mahdhaoui A, Laznik MC, Apicella F, et al. Do parentese prosody and fathers' involvement in interacting facilitate social interaction in infants who later develop autism? PLoS One (2013) 8:e61402. doi:10.1371/journal.pone.0061402

49. Frick PJ, White SF. Research review: the importance of callous-unemotional traits for developmental models of aggressive and antisocial behavior. J Child Psychol Psychiatry (2008) 49:359-75. doi:10.1111/j.1469-7610.2007.01862.x

50. Guilé JM. Perturbations précoces de l'intersubjectivité et de l'empathie: quels liens avec les troubles externalises de l'enfant et de l'adolescent. Ann Med Psychol (2007) 165:412-9. doi:10.1016/j.amp.2007.05.001
51. Cheng Y, Hung A, Decety J. Dissociation between affective sharing and emotion understanding in juvenile psychopaths. Dev Psychopathol (2012) 24:623-36. doi:10.1017/S095457941200020X

52. Decety J, Skelly LR, Kiehl KA. Brain response to empathy-eliciting scenarios involving pain in incarcerated individuals with psychopathy. JAMA Psychiatry (2013) 70:638-45. doi:10.1001/jamapsychiatry.2013.27

53. Sebastian CL, McCrory EJ, Dadds MR, Cecil CA, Lockwood PL, Hyde ZH, et al. Neural responses to fearful eyes in children with conduct problems and varying levels of callous-unemotional traits. Psychol Med (2014) 44(1):99-109. doi:10.1017/S0033291713000482

54. Ramchandan IP, O'Connor T, Evans J, Heron J, Murray L, Stein A. The effects of pre- and post-natal depression in fathers: a natural experiment comparing the effects of exposure to depression on offspring. J Child Psychol Psychiatry (2008) 40(10):1069-78. doi:10.1111/j.1469-7610.2008.02000.x

55. Blair R, Colledge E, Murray L, Mitchell D. A selective impairment in the processing of sad and fearful expressions in children with psychopathic tendencies. J Abnorm Child Psychol (2001) 29:491-8. doi:10.1023/A:1012277125119

56. Dadds M, Perry Y, Hawes D, Merz S, Riddell A, Haines D, et al. Attention to the eyes and fear-recognition deficits in child psychopathy. Br J Psychiatry (2006) 189:280-1. doi:10.1192/bjp.bp.105.018150

57. Guilé JM, Cohen D. Les perturbations de l'empathie sont au cour des troubles des conduites de l'enfant et de l'adolescent. Neuropsychiatrie Enf Adolesc (2010) 58:241-7. doi:10.1016/j.neurenf.2008.09.007

58. Cohen D. Probabilistic epigenesis: an alternative causal model for conduct disorders in children and adolescents. Neurosci Biobehav Rev (2010) 34:119-29. doi:10.1016/j.neubiorev.2009.07.011

59. Tanaka JW, Wolf JM, Klaiman C, Koenig K, Cockburn J, Herlihy L, et al. Using computerized games to teach face recognition skills to children with autism spectrum disorder: the Let's Face It! program. J Child Psychol Psychiatry (2010) 51:944-52. doi:10.1111/j.1469-7610.2010.02258.x

Conflict of Interest Statement: The author declares that the research was conducted in the absence of any commercial or financial relationships that could be construed as a potential conflict of interest.

Received: 06 November 2013; paper pending published: 27 November 2013; accepted: 12 January 2014; published online: 27 January 2014.

Citation: Guilé JM (2014) Probabilistic perception, empathy, and dynamic homeostasis: insights in autism spectrum disorders and conduct disorders. Front. Public Health 2:4. doi: 10.3389/fpubh.2014.00004

This article was submitted to Child Health and Human Development, a section of the journal Frontiers in Public Health.

Copyright (c) 2014 Guilé. This is an open-access article distributed under the terms of the Creative Commons Attribution License (CC BY). The use, distribution or reproduction in other forums is permitted, provided the original author(s) or licensor are credited and that the original publication in this journal is cited, in accordance with accepted academic practice. No use, distribution or reproduction is permitted which does not comply with these terms. 